\title{
DESARROLLO Y DEMOCRACIA EL ESTADO DE LA RELACION POST- REFORMAS
}

\author{
Diego Martín Raus*
}

enviado: Junio 2011- aceptado: Agosto 2012

\begin{abstract}
Resumen
Este trabajo analiza los cambios conceptuales, institucionales y políticos que afectaron a la relación entre desarrollo y democracia en América Latina luego, y como resultado, de las reformas económicas de los '90 (Consenso de Washington).

La sociología, la politología y la economía del desarrollo (CEPAL) tuvieron su auge en la década de los `50 al igualar, conceptualmente y como programa político, la relación entre desarrollo económico- modernización social- gobernabilidad política y estabilidad democrática. Este paradigma se vio interesadamente deconstruido en los `90 a partir de los efectos sociopolíticos que atravesaron negativamente a las sociedades latinoamericanas con la reincorporación de la economía de mercado (neoliberalismo). Analizar esa operación discursiva y política es el objetivo de este trabajo.
\end{abstract}

Clasificación JEL: O1, O43

Palabras clave: desarrollo- sociedad- modernización- reformas económicas- democracia

\begin{abstract}
In this paper I consider the politics, institutional and conceptual changes that concerns the relationship between development and democracy in Latin America, after, and as a consequence, of economic reforms in the '90 (Washington Consensus).
\end{abstract}

\footnotetext{
*Universidad Nacional de Lanús, Departamento de Planificación y Políticas Públicas, Director Licenciatura en Ciencia Política y Gobierno, e.mail: dmraus@yahoo.com.ar
} 
Sociology, political sciences and the economy of development (ECLA) related, in the '50, and as a virtuous circle, the relationship among economic development- social modernization- governability-democracy stability. This conceptual and political model was reversed in the '90 from the sociopolitical effects that negatively went through latin American societies with the return of free market economic policies (neoliberalism). To analyze and discuss this conceptual and political operation is the goal of this work.

JEL Classification: O1, O43

Key Words: development- society- modernization- economic reforms- democracy

\section{INTRODUCCION}

La relación entre desarrollo y democracia fue fundante de la sociología académica en el contexto latinoamericano y, a falta de una ciencia política, la resolución de la relación mencionada en los marcos epistémicos de la sociología política. El encuadre genérico en término de las ciencias sociales lo constituyó la denominada Teoría de la Modernización. La inevitable influencia externa provino de la predominancia de los análisis estructural-funcionalistas desarrollados en la academia norteamericana. Concretamente, la posibilidad de pensar ambos términos de manera relacional impulsaron las ciencias sociales de América Latina e institucionalizaron espacios importantes en las universidades, centros de investigación y organismos multilaterales como la CEPAL.

La pregunta que se podría formular en el marco de este desarrollo institucional sería interrogar sobre la novedad que introducirían estas instituciones en la cuestión del desarrollo y la democracia, más allá de su lectura relacional. Después de todo constituyen conceptos que atravesaron las sociedades industriales del siglo XIX.

Si ese fuera el interrogante, una posible respuesta estribaría en situar el valor agregado de esta cuestión en haber posicionado a uno de los términos desarrollo- como condición necesaria del otro -democracia-. Por otra parte, esta modalidad de establecer la relación redefinió ambos conceptos otorgándoles una nueva potencialidad política al tiempo que la síntesis evolutiva de ambos se constituyó en una teleología de la modernización latinoamericana. Así como los ciclos de Rostow enmarcaron las etapas a seguir para cualquier economía industrial (cenit de la modernidad económica), la articulación y evolución del desarrollo y la 
democracia se conformó en el cenit de la modernidad social y política a la que toda sociedad debería tender. Una sociedad industrial con desarrollo social (modernización y movilidad social) y democracia fue el tipo ideal weberiano de las sociedades occidentales de posguerra, sea en su versión Centro (desarrollo) o en la versión Periferia (en desarrollo).

Detengámonos entonces en la idea axial de este paradigma que señala al desarrollo como la condición necesaria y suficiente de la democracia, pues dicho paradigma constituyó el principio orientador de las políticas desarrollistas en América Latina.

La base material del paradigma modernizador lo constituyó el modelo de industrialización por sustitución de importaciones (ISI) que se desplegó en algunos países del área a partir del cierre del comercio internacional producto de la crisis del '30 y el reacomodamiento de las economías centrales al keynesianismo. La oportunidad del proceso industrializador fue conceptualizado (Raúl Prebisch desde la CEPAL) como la condición del desarrollo económico y social en América Latina y la vía para acortar las distancias entre el Centro (economías capitalistas desarrolladas) y la Periferia (economías en vía al capitalismo en desarrollo).

Este concepto de desarrollo, en las condiciones específicas en que se desplegó ${ }^{1}$, implicó una lógica que excedió el campo de lo económico. La condición de posibilidad del desarrollo económico, a la vez que el objetivo del mismo, era la modernización social. Concretamente, se igualaba el despliegue de la economía industrial con la integración de nuevos y vastos sectores sociales al espacio urbano, generador de bienes sociales, culturales y políticos que agregaban ciudadanía a la asalarización del mercado de trabajo.

La incorporación de nuevos grupos sociales al mercado de trabajo asalariado y a una sociedad política (modelo de estado) que proveía de bienes públicos que permitían complementar al mercado a la vez que garantizar (derechos de ciudadanía) esa inclusión, producía dos efectos netos: por un lado la idea de la movilidad social ascendente ${ }^{2}$ que orientaba y legitimaba una nueva lógica de la acción colectiva, y por otro lado una apreciación del contexto político en que se desplegaba esa dinámica, que era la democracia política. Se igualaba así ambos polos de la relación: la modernización era democracia y viceversa.

\footnotetext{
${ }^{1}$ Básicamente la orientación hacia el mercado interno y, de ahí, la posibilidad de armonizar, como condición del desarrollo, territorios y grupos sociales.

2 Concepto liminar de la sociología de la modernización que implicaba que ese proceso no solo era material sino también constructor de una subjetividad social específica.
} 
La modernización social se expresaba en las formas evolutivas de la estratificación social. Mas aún, la ciencia social en América Latina pudo incorporar los conceptos de estructura social y estratificación social, pues la economía industrial incorporaba al conjunto de la población a partir del mercado de trabajo, en posiciones cada vez más diversificadas y con niveles de movilidad, sobre todo educativas, dinámicos.

Esta modernización, que elevada al plano político generaba la condición de posibilidad de acuerdos legales y legítimos, esto es la democracia como escenario del consenso y el conflicto, era visto como un desarrollo cierto a la vez que ineludible. La nueva dinámica social y política era el destino cierto de América Latina, más allá de los acomodamientos y las asincronías con que dicho proceso se desenvolvía. La modernización era el cambio, y el cenit del cambio era la democracia política ${ }^{3}$.

Al poco tiempo de desplegarse la Teoría de la Modernización surgieron perspectivas críticas ${ }^{4}$. El denominador común de ellas, algunas como las de O’Donnell basada en la realidad del momento, señalaba que si bien la industrialización había promovido una modernización social y cultural evidente, eso no implicaba, o no conducía, directamente a la democracia política. El punto, para estas perspectivas, es que el proceso de modernización había sido tan dinámico y, a veces, desordenado, que las sociedades latinoamericanas no habían podido adaptar sus instituciones políticas, permeadas por el tradicionalismo católico-hispano, a las nuevas realidades sociales más seculares y movilizadas. Esta tensión entre lo económico y social y lo político conducía o a atenuar el desarrollo modernizador, algo difícil por el empuje estructural del mismo, o a sacrificar las instituciones democráticas hasta que el autoritarismo que necesariamente debía instalarse, generara un orden social más acorde con el lento desarrollo de las instituciones democráticas.

No obstante este debate, lo que nos interesa señalar es el convencimiento analítico y político de la necesaria relación entre desarrollo (como modernización)

\footnotetext{
${ }^{3}$ Por supuesto que el contexto de apreciación de la democracia como punto de arribo del cambio modernizador, lo constituía la tradición política caudillesca y autoritaria de la historia política latinoamericana.

${ }^{4}$ Para abreviar la también voluminosa bibliografía, Huntington, S.: El orden político en la sociedad en cambio, Paidos, Bs. As., 1972; O’Donnell, G.: Modernización y autoritarismo, Paidos, Bs.As., 1982. Desde una perspectiva totalmente opuesta, Cardoso, F. y Faletto, E.: Desarrollo y subdesarrollo en América Latina, Siglo XXI, Bs.As., 1984.
} 
y democracia. Aún las perspectivas críticas situaban su punto de discusión no en la validez del paradigma sino en la coyuntura histórica en que se desplegaba. Superada esa coyuntura, la relación se reconstituiría incluso en una perspectiva clasista.

El tercer cuarto del siglo XX en América Latina se desenvolvió con el convencimiento de una relación causal entre desarrollo y democracia. Los puntos del debate consistieron en dilucidar y superar las tensiones que esa necesaria relación producía temporariamente. Mas aún, una mayor tensión política como producto del desarrollo era un signo de que éste era más dinámico. La variable de ajuste era política. La meta, sociedades modernas y democráticas como los modelos de Welfare State europeos, ameritaba lo sinuoso del camino.

El último cuarto del siglo XX destrozó aquel paradigma. No quizás en lo discursivo pero si en el terreno económico y social. La utopía modernizadora estalló paradójicamente en la misma medida que se estabilizaban las democracias latinoamericanas. La democracia política en América Latina, imperfecta en lo sustantivo pero estable en lo formal, es un bien público en proceso de transformarse en un valor adquirido. Pero ya no se la piensa, ni se la administra, en relación al desarrollo. Al menos las modalidades del desarrollo transmutaron de tal manera que hay que ser muy cuidadoso para relacionar estrechamente desarrollo y democracia, por el riesgo de deslegitimar a ésta última.

Sobre la reconfiguración, estructural y semántica, de la relación entre desarrollo y democracia, versa este trabajo.

\section{LAS REFORMAS ECONOMICAS Y LA RUPTURA DE LA RELACION OPTIMISTA}

El punto de partida es la constatación del hecho que las políticas de reformas económicas implicaron cambios en las modalidades de estructuración del mercado de trabajo y en las capacidades diferenciales de apropiación de ingresos de los grupos sociales, lo cual conllevó al aumento cuantitativo y a la redefinición cualitativa de la situación de pobreza. Esto, junto al proceso de reforma de los estados, que en los hechos implicó un cierto "desentendimiento" de los problemas sociales, generó un efecto de marginación social, entendido como un proceso de desinstitucionalización de grupos sociales, que agudizó las situaciones de pobreza.

Si se acuerda que tal tipo de exclusión, aparte de novedosa en los países del área, es potencialmente disruptiva en términos de gobernabilidad y consolidación 
democrática, el punto pasa por evaluar las políticas específicas que implementan algunos países, sobre todo las relacionadas con el mercado de trabajo, para reinstitucionalizar sectores sociales.

Las políticas de ajustes estructurales en América Latina, realizadas dentro del marco genérico denominado "Consenso de Washington"5, implicaron reformas económicas ${ }^{6}$ que definieron una nueva matriz socioeconómica en la región. Está se define por una extendida privatización de la economía, un agudo proceso de desregulaciones estatales de la misma, una articulación estrecha al nuevo orden económico internacional (globalización), una aceleración de los intercambios comerciales y los flujos financieros y un salto tecnológico que implicó nuevos sentidos de competitividad y aumentos en la productividad.

En términos socioeconómicos, estas transformaciones supusieron un achicamiento de los espacios públicos y los esquemas conceptuales con que los actores definían el sentido del crecimiento económico, una individuación y racionalización $^{7}$ de las relaciones socioeconómicas y una significativa disparidad en la distribución de los ingresos globales y en las capacidades de inserción en el nuevo mercado laboral y de consumo.

En este último aspecto es que las reformas económicas se ligan estrechamente a ciertas transformaciones sociales, esencialmente las relacionadas con el mercado de trabajo y las condiciones estructurales de la pobreza. Si bien un cierto sentido común extendido relaciona directamente a las reformas económicas con el aumento del desempleo y la pobreza, mas acertado es, creemos, constituir la relación en términos de transformaciones económicas y cambios en la estructuración de los mercados de trabajos y en las modalidades de captación social de ingresos, lo cual redefine las características estructurales de la pobreza.

Lo antedicho implica aceptar que esas problemáticas sociales deben ser pensadas de manera diferente a las tradicionales. Si lo significativo son las nue-

\footnotetext{
${ }^{5}$ Las características de este "Consenso" y el contexto en el que fue definido, en Bresser Pereira, L.: La crisis de América Latina: Consenso de Washington o crisis fiscal?, Revista Pensamiento Iberoamericano N 19, España, 1991.

${ }^{6}$ Entendida conceptualmente la idea de "reforma económica” como una situación en la que se articula una nueva estructura económica con un cambio acorde en los comportamientos económicos de los actores sociales.

${ }^{7}$ En el sentido de la teoría de la acción racional y sus consecuencias en las decisiones públicas y la generación de bienes colectivos.
} 
vas modalidades con que se estructura el mercado de trabajo y las consecuentes transformaciones en las posibilidades de captar ingresos de los grupos sociales, el problema no es solo la dimensión cuantitativa de esos aspectos sino también los nuevos parámetros a definir para constituir una situación social como injusta y políticamente conflictiva.

Por otra parte, esta redefinición de las relaciones y problemáticas sociales vuelven a poner en un plano protagónico de análisis a la cuestión de la gobernabilidad social y a la democracia como proceso en vías de consolidación. En esta aspecto partimos de la idea de suponer escindidas ambas cuestiones en términos políticos, es decir, que por primera vez en la historia política latinoamericana es posible pensar que los conflictos sociales no apuntan a la legitimidad del régimen democrático sino a la eficacia política de los gobiernos de darles respuestas institucionales.

Por último, planteamos que esta construcción del concepto y la acción de gobernabilidad no es necesariamente conservadora $^{8}$, sino que debe entenderse como la capacidad institucional de los gobiernos de atender demandas sociales de resolución de situaciones conflictivas o de cambio, en donde el objetivo político no sea la restauración del equilibrio sino la incorporación de los planteos y las diferencias que muchos de ellos expresan. Esta capacidad política no solo implica una situación de gobernabilidad sino que tiende a la legitimidad del sistema político y a un reconocimiento de las potencialidades de la democracia como único escenario político.

Paradójicamente los sucesos sociales y políticos de los últimos años en América Latina, ponen en cuestión, principalmente, las posibilidades de gobernabilidad de los países de la región, y no a la democracia, o a la democratización, como tema en sí mismo y como régimen político. La sensación que producen las políticas adoptadas es que la democracia no es el problema principal de la agenda política, y esto no por pensarla como un régimen político definitivamente consolidado, sino que el fin último de esas políticas es generar las condiciones globales suficientes para hacer gobernables a sociedades donde el punto de partida, y prácticamente lo único que no está en discusión, son los cambios económicos puestos en marcha, al parecer, de manera estructuralmente irreversible ${ }^{9}$.

\footnotetext{
${ }^{8}$ Es decir, al estilo funcionalista, donde la gobernabilidad implica una acción política que tienda a diluir las demandas sociales de cambio reestableciendo el equilibrio del sistema global, o en una visión política tal cual la plantea Huntington en el Documento Trilateral o en la bibliografía aquí citada.

${ }^{9}$ En este punto creo oportuno asumir las tesis de algunos de los trabajos de Cavarozzi, donde plantea la crisis definitiva de lo que denomina "Matriz de Estado autocentrado" o "Matriz Estado-Céntrica", Ver
} 
Pero esta situación paradojal es doble puesto que, así enunciada, se podría agregar, como razonamiento lógico, que las posibilidades de hacer gobernable una sociedad depende de la consolidación de la democracia como patrón de institucionalización del sistema político. Sin embargo trataremos de desarrollar esta problemática desde dos líneas de análisis: por la primera entender que gobernabilidad y democracia, tanto en sus efectos inductores de políticas como en sus aspectos simbólicos que hacen a la constitución de espacios de intercambios públicos, son dos variables, si no diferenciadas, con especificidades propias. Por el otro lado pensar que hacer gobernable una sociedad puede ser un proceso político que se autonomice relativamente de la democracia y que, por ende, puede haber más de una modalidad de gobernabildidad política, y esto sin alterar un proceso de democratización, sea transicional o consolidado.

Pero también debemos aclarar el punto de partida. Este, que debe ser apreciado no en relación de determinación sino de aspectos constituyentes de un mismo sujeto, emerge de los profundos cambios que la región ha venido atravesando desde los '80 en sus dimensiones económicas y sociales. Estos cambios se originan en aspectos externos e internos de cada país y, en tanto tales, generan en la superficie pública un variado conglomerado de nuevos actores, demandas, lógicas de razonamiento y procesamiento de realidades percibidas como diferentes, problemas de desarrollo, crecimiento y distribución económica, la tensión entre la globalización económica y la fragmentación social10, desafíos a la representatividad y a la legitimación de lo político, etc.. Es decir, dejar en claro puntos de partida que eviten aproximaciones y construcciones sobre el sistema político como si sus crisis y redefiniciones estuvieran autogenerados. Evitar el politicismo tan habitual hoy por ser moda intelectual y que no es más que la otra cara del economicismo que, con justa razón, ya no es tan habitual.

Cavarozzi, M.: Beyond the transitions to democracy. ponencia presentada en el XV Congreso Mundial de Ciencia Política, Bs. As., Julio de 1991; también Cavarozzi, M.: Transformaciones de la política en la América Latina contemporánea, ponencia presentada en el XIX Congreso Latinoamericano de Sociología (ALAS), Caracas, Venezuela, Junio de 1993. Creo también que es necesario enfatizar que esa perspectiva de crisis final debe sustentarse no solo en el cambio de los patrones tecnológicos y productivos de la economía, así como en las modalidades predominantes de regulación de las mismas, sino también en la redefinición de los patrones de constitución de identidades sociales, y esto no solo en la relación laboral sino en todo el sistema cultural-normativo que permea esos procesos constitutivos. Creo que este punto adquiere tal dimensión que se transforma en una discusión en si misma. Ver Raus, D.: Acerca de la constitución de identidades sociales, Revista Doxa N* 9-10, Bs. As., Verano 1993-94.

${ }^{10}$ Tal cual lo señala Lechner en: Lechner, N.: El debate sobre Estado y Mercado, Rev. Nueva Sociedad N* 121, Caracas, Setiembre-Octubre 1992. 


\section{LAS POLITICAS DE REFORMA ECONOMICA}

Es de sentido común señalar que en la década de los '80 los países latinoamericanos se involucraron en profundos cambios en sus estructuras económicas. Estos procesos de reestructuración habían comenzado en la mayoría de los países del OCDE en la década del '70 a consecuencias de la caída de la productividad y, por ende, de la eficiencia de la economía en su conjunto, y significaron en términos generales alterar las regulaciones macroeconómicas características del modelo económico keynesiano, introducir nuevas tecnologías y procesos de trabajo, redefinir los sectores estatales y privados de la economía, controlar el déficit fiscal y comercial, manejo de la tasa de interés, etc.. Pero fundamentalmente estos cambios internos, sumados a procesos como el desarrollo del sector financiero, generaron una profunda transformación del sistema económico internacional. Esta se resume en la idea de globalización de la economía, la cual refiere a la completa internacionalización de todos los aspectos que hacen al desarrollo de un proceso económico productivo. De ahí en más la economía dejó de ser una cuestión de empresas y sectores, para pasar a involucrar a gobiernos, acuerdos regionales e internacionales, sistemas de comunicaciones, horizontes de previsibilidad y confiabilidad, etc..

Obviamente América Latina no podía escapar de esta reestructuración. Sin afirmar esto por relaciones de dependencia económica y política o por la vecindad con EE.UU., basta acordar que los cambios en un sistema económico que, por ellos, se globaliza, involucra a países y regiones, a excepción de aquellos que se cierren en sistemas de autosubsistencia, algo casi totalmente improbable en razón de la misma globalización.

Hay cierto acuerdo generalizado que coincide en señalar dos marcos externos que condicionaron las modalidades reconversoras: las "recetas" puntuales, es decir país por país11 del FMI y el denominado "Consenso de Washington”. Por sus características políticas, en términos de relaciones internacionales, este último se convirtió en el patrón generador de grandes linealidades políticas a tener en cuenta por los gobiernos de la región.

El "Consenso de Washington” es novedoso en tanto define políticas macro en torno a la situación de crisis de las economías latinoamericanas, la inviabilidad de los regímenes militares para generar ordenamientos económicos estables y la

11 El diagnóstico de las economías y los monitoreos permanentes sobre los cambios en marcha que el FMI entabla individualmente con los países de la región obedecían, aparte de la lógica económica, a una estrategia política: impedir que estos se nuclearan en un Club de Deudores. 
conciencia creciente acerca de la necesidad de los países de la región de comenzar un proceso duradero y difícil de fuertes cambios estructurales. La única certeza a mano a principios de los '80 era la definitiva crisis del modelo económico de crecimiento "hacia adentro" y de la estructura político-institucional que aquellos habían generado. Por último la denominación de estas nuevas linealidades a seguir, esto es "Consenso", marcaba las pautas no solo de la inviabilidad del autoritarismo para generar esos cambios sino también los términos en que se iba a desarrollar esas negociaciones entre EE.UU. y América Latina. A su vez estos términos implicaban un largo plazo que reflejaba la densidad e intensidad de los cambios socioeconómicos por venir.

El diagnóstico de crisis para América Latina se situaba en torno a las excesivas regulaciones del Estado, las cuales fueron incrementándose paralelamente al desarrollo del modelo sustitutivo, y que desembocaron en una alta como ineficiente intervención en la economía, sea desde las empresas públicas como desde las regulaciones macroeconómicas y administrativas. Ambas dos, acorde al diagnóstico, tornaron ineficiente la economía privada por el proteccionismo y los subsidios concedidos, a la vez que rigidizaron la estructura económica de manera tal que ésta no puede acompasarse a las nuevas señales macrotendenciales de la economía mundial: globalización, exportaciones, flexibilidad del proceso productivo y competitividad. Así se constituye la crítica a la ineficiencia estatal cristalizada en el déficit fiscal y las recurrentes altas tasas de inflación.

Pero también, siempre en torno al diagnóstico del "Consenso”, parte del problema residía en la intervención social del Estado, la cual, dado su intervencionismo económico, provocaba que el Estado se hiciera cargo de los costos sociales laborales y no laborales, políticas públicas que una vez asumidas por la sociedad se transforman en legitimidad político-estatal y por ende pasan a ser dificultosas de ser dejadas de lado, incluso recortadas. Esta constituye la crítica hacia el sesgo populista de los estados latinoamericanos.

Según Bresser Pereira12 “...el Consenso de Washington estaría constituído por 10 reformas: 1- disciplina fiscal tendiente a eliminar el déficit público; 2- cambio en las prioridades en relación al gasto público, eliminando subsidios y aumentando gastos en salud y educación; 3- reforma tributaria, aumentando los impuestos si esto fuese inevitable...; 4- los tipos de interés deberían ser positivos y determinados por el mercado; 5- el tipo de cambio debería ser también determina-

\footnotetext{
${ }^{12}$ Bresser Pereira, L.: La crisis de América Latina. Consenso de Washington o crisis fiscal?, en Pensamiento Iberoamericano- Revista de economía política N* 19, Enero-Junio 1991, España.
} 
do por el mercado, garantizándose al mismo tiempo que fuese competitivo; 6- el comercio debería ser liberalizado y orientado hacia el exterior; 7- las inversiones extranjeras directas no deberían sufrir restricciones; 8- las empresas públicas deberían ser privatizadas; 9- las actividades económicas deberían ser desreguladas; 10- el derecho de propiedad debería ser garantizado más firmemente.

Surge del análisis que estas medidas aconsejadas por el "Consenso" suponen una profundísima reconversión de las linealidades del desenvolvimiento económico latinoamericano. Las tasas de interés positivas implican el fín del desarrollo económico industrial sustitutivo de mercado interno, el cual se expandió en base a las tasas de interés negativas o "créditos blandos”. La disciplina fiscal anula el crecimiento económico en base a una inflación controlada, si bien es obvio señalar que en las dos últimas décadas el control de la inflación era más una utopía que un instrumento económico. La disciplina tributaria opera en el sentido de financiar el gasto público con recursos genuinos y no inflacionarios. La privatización de las empresas públicas no solo constituyó un mecanismo para hacer cobrable las deudas externas, a partir de la utilización de bonos de la deuda en la compra de empresas estatales, sino también posibilitó la retirada del Estado en la economía y en la regulación de algunos precios de servicios y la disminución del gasto público. Si a esto se le suma la no restricción a las inversiones externas y la paulatina desaparición de otros mecanismos de regulación jurídicos y administrativos, queda claro que la idea liminar pasaba por insertar a las economías latinoamericanas en el modelo de la globalización.

Pero la otra emergencia del análisis consiste en la constatación que, incluso con las especificidades que surgen de cada caso y de sus particularidades históricas en referencia al desarrollo económico, los países latinoamericanos aceptaron tanto el diagnóstico del "Consenso" como la mayoría de sus recomendaciones, al punto que esta aceptación se transformó en estrategias político-gubernamentales y en políticas públicas concretas de privatización de las economías. Puede pensarse que estas estrategias surgen de un "mix" entre el convencimiento de la efectiva decadencia, en términos de posibilidades y condiciones, de las regularidades económicas y políticas del modelo sustitutivo, y las relaciones de predominancia entre el centro económico y la periferia que, esta vez, se expresan como presión no desde las amenazas al proceso democrático, sino desde el peso de las deudas externas y las condiciones para integrarse a un mundo totalmente interactivo en lo económico. 
De una u otra manera desde la segunda mitad de los '80 los países latinoamericanos privilegian definitivamente el proceso de reestructuración económica ${ }^{13}$. Esta especial atención política implica en el corto plazo grandes modificaciones: privatizaciones de empresas públicas -proceso generalizado en Argentina a pesar de que poco tiempo antes resultaba impensable dada la fuerza sindical del sector, no tan global en otros países (Uruguay veta en un referendum público la privatización de los teléfonos, mientras que el gobierno brasileño no sostiene la privatización de sectores estratégicos igual que Chile con el cobre y Venezuela con el petróleo)-; control de la inflación y del déficit fiscal -por lo cual las principales medidas macroeconómicas pasan a estar supeditadas a estos dos requerimientos-; apertura de las economías y búsqueda de acuerdos regionales para suplantar mercados internos a la vez que recostarse en la globalización económica; se deja de considerar al empleo estatal como un paliativo del desempleo por lo que se reducen los plantas laborales públicas; creación de escenarios económicos y jurídicos aptos para la inversión extranjera ${ }^{14}$ y generación de mercados financieros atractivos para soportar los déficits comerciales y de balanza de pagos producto de las aperturas de mercados y del pago de la deuda. En definitiva se fueron produciendo, y consolidando, cambios estructurales que a su vez generaron paulatinos cambios en la conducta, la denominada racionalidad, de los actores económicos. Y esto, más allá de las muchas cuestiones que seguiremos abordando, pareciera implicar la casi definitiva imposibilidad de volver atrás en el proceso de reestructuración económica ${ }^{15}$.

\footnotetext{
${ }^{13}$ Hemos sostenido en otro trabajo que esta tarea implica una "segunda ola” de gobiernos democráticos en la región, la cual emerge de la constatación de que fue la crisis económica la que desarticuló gravemente la "primera ola" de gobiernos, los cuales se habían estructurado y legitimado en las tareas de la transición a la democracia. De esa situación los casos argentino y peruano fueron paradigmáticos. Ver Raus, D.: La paradoja latinoamericana: gobiernos no neoconservadores con políticas neoconservadoras del orden social, Documento de trabajo N* 58 EURAL, Bs. As. 1994.

${ }^{14}$ Es casi obvio contrastar la apelación a este instrumento económico como motor del crecimiento respecto a las posiciones que sobre el capital multinacional se tenía en los '60-'70, incluso sin llegar a las posiciones de la teoría de la dependencia.

${ }^{15}$ Es necesario aclarar una vez más que el proceso de crisis y transformación económica no afectó a todos los países por igual, ni todos los países inmersos en aquellos optaron por las mismas políticas de ajuste. No obstante se puede hablar de la región en general por varios motivos: sea porque la magnitud de los cambios en algunos países preponderantes, Brasil, Argentina, más la apertura económica y los acuerdos regionales involucran a casi toda la región en cuanto a la performance e impactos económicos, sea porque los reordenamientos sociales que se producen implican movimientos que atraviesan la región, sea porque las comunicaciones alteran los nichos culturales a la vez que los sucesos que transmiten entre países vecinos operan como efectos demostrativos y, por ende, inducen sus agendas políticas, o sea, en definitiva, porque las estrategias políticas que los países desarrollan impactan necesariamente en los otros aunque más no sea por esa "ley” histórica acerca del “efecto dominó” que los ciclos políticos tienen en América Latina.
} 
Ahora bien, estos cambios enunciados en políticas económicas implican también datos ciertos, que aparte de señalar la magnitud de las transformaciones en clave de más o menos éxito económico, encierran procesos que necesariamente deben repercutir sobre los ordenamientos y acciones de los actores sociales.

Una primera pregunta para indagar en la lógica subyacente en las reformas económicas consiste en pensar la prioridad asignada a las políticas antiinflacionarias y cambiarias, es decir, la necesidad de estabilidad macroeconómica.

La respuesta obvia es que las políticas antiinflacionarias tendieron a contrarrestar el diagnóstico de crisis que se realizó sobre la región y que estaba centrado en las políticas monetarias expansivas y sus efectos en las altas inflaciones (o híper) en América Latina. Pero también es cierto que el énfasis puesto en el control de la inflación, y lo que esto implica en el equilibrio del déficit fiscal, obedecía a la necesidad de generar un nuevo ordenamiento económico que se caracterizaba por la lógica de la oferta en la producción de bienes y servicios, el progresivo retraimiento del gasto estatal, sobre todo el gasto distributivo, el crecimiento no inflacionario y el ajuste socioeconómico a la disciplina fiscal. Es decir, exactamente a la redireccionalización de las economías latinoamericanas del período populista-desarrollista.

Estas políticas observaron una etapa transicional con los planes heterodoxos de Argentina, Perú y Brasil (Plan Austral, Inti y Cruzado respectivamente) a mitad de los '80. Su fracaso, debido a la imposibilidad del Estado de controlar la expansión del gasto y la inflación, generó las condiciones políticas necesarias para aplicar programas ortodoxos cuya primera medida consistía en forzar al Estado a observar disciplina fiscal y monetaria y permitir el traspaso de las variables macroeconómicas y productivas al mercado.

Para entender genéricamente a las políticas de reformas económicas hay que observar la prioridad absoluta que se le otorga al control de la inflación y al sostenimiento de una política cambiaria real y estable. Luego es necesario analizar el impacto estructural de estas políticas, en sí mismas, y como punto de partida de nuevos ordenamientos económicos.

La estabilidad buscada con el control de la inflación y un tipo de cambio establecido primero como política estatal y luego mantenido vía mercado, implicaba la condición necesaria para recuperar el valor de la moneda, la capacidad de generar precios reales y orientados al mercado internacional, atraer inversiones, poder exportar y, definitivamente, introducir la variable certidumbre en economías 
tradicionalmente inestables y cíclicas ${ }^{16}$. La estabilidad monetaria es la posibilidad de interactuar en la nueva economía globalizada.

Existían, en estos intentos, factores extraeconómicos importantes a desarrollar: demostrar la voluntad de un ordenamiento definitivo de las economías latinoamericanas, dejar de lado definitivamente el modelo de crecimiento protegido (que implicaba discrecionalidad estatal en el manejo monetario), orientar los comportamientos económicos de los actores sociales mas dinámicos en la tendencia marcada por la globalización y, así, hacerse acreedor a la confianza de los organismos multilaterales de crédito para resolver la cuestión que había disparado las crisis económicas en la región: las deudas externas.

La necesidad del control de la inflación dotó a los programas de reformas de un fuerte sentido de control monetario, sobre todo en lo que respecta al equilibrio del gasto fiscal ${ }^{17}$. La dependencia de la economía del equilibrio fiscal condicionó no solo las políticas de ajuste estructural sino también los gastos estatales destinados al desarrollo social. La cuestión del gasto público, la tasa de ahorro interno y el financiamiento externo se convirtieron en las variables determinantes del resto de la economía y de las políticas sociales así como del salario que, en el mismo sentido que otras variables, intentó ser transformado en una relación de mercado y alejado de las políticas de Estado. Incluso, ante la disyuntiva entre medidas de política económica tendientes al crecimiento y la competitividad pero de posible impacto en el equilibrio monetario y/o fiscal se le da prioridad a éste ${ }^{18}$. La credibilidad se transformó en la condición de éxito de las economías en proceso de reformas.

Esta estabilidad monetaria y financiera implicó una reorientación de los roles económicos, y sociales, del Estado, la orientación de la dinámica económica hacia los mercados externos, la necesidad de rediseñar las instituciones económicas públicas y privadas y, entre ellas, una progresiva transformación en las modalidades sociales de realización de los contratos económicos.

A la estabilidad macroeconómica se le añaden las políticas específicas de ajuste estructural. Estas son las privatizaciones, las políticas de desregulaciones,

\footnotetext{
${ }^{16}$ América Latina y el Caribe. A diez años de la crisis de la deuda, Informe banco Mundial, Washington D. C., 1992.

${ }^{17}$ Frenkel, R.: Las políticas antiinflacionarias en América Latina, Revista Agora № 5, Bs.As., 1996.

${ }^{18}$ Gerchunoff, P. y Torre, J.C.: La política de liberalización económica en la administración de Menem, Desarrollo Económico N¹43, Bs.As., Octubre-Diciembre 1996.
} 
las aperturas comerciales y las reformas financieras. En conjunto, la introducción de estas reformas implican una nueva estructura económica, la cual se define por una redefinición de sectores y actividades económicas, otras instituciones y cambios en los comportamientos económicos.

La apertura comercial y las desregulaciones implicaron dejar atrás el crecimiento "hacia adentro", protegido por políticas estatales. Este, si bien exitoso en muchos países en cuanto a generar una estructura industrial, modelaron economías con precios no competitivos en el mercado mundial, lo cual desalentaron las exportaciones, la innovación tecnológica y la diversificación de la misma producción interna ${ }^{19}$. Por otra parte, la protección industrial implicó también políticas cambiarias cuya lógica era desalentar las importaciones, efecto que al lograrse producía cambios en los precios relativos y tenía efectos inflacionarios. En este sentido puede observarse la articulación en los procesos de reformas económicas entre la estabilidad monetaria y los ajustes estructurales.

A su vez las desregulaciones fueron promovidas con el objetivo de bajar los costos "indirectos" de la producción, es decir aquellos costos causados por un exceso burocrático en la circulación de bienes y transacciones ${ }^{20}$. El diagnóstico es que la tendencia natural de toda actividad en la que interviene el Estado es hacia la burocratización de la misma, por lo cual se generan mecanismos e instituciones que exceden en mucho los objetivos iniciales de la regulación. Este exceso se transforma paulatinamente en costos adicionales en las transacciones que, inevitablemente, terminan pagando las empresas y luego, vía precios, la sociedad. El corolario es que la excesiva y distorsionada regulación deviene en caída de la competitividad pero también es inflacionaria.

El nuevo orden económico internacional implica una internacionalización de las economías a nivel mundial. En ese orden es necesario precios y tipos de cambios estables, pero también competitividad en la producción. Lograr esta competitividad exige ajustar costos internos de producción y adecuarlos a los estándares internacionales ${ }^{21}$. Desde la visión del consenso predominante la condición de posibilidad de la competitividad en economías de mercado, requiere un grado de apertura de manera que la disciplina de mercado posicione sectores y empresas

19 Edwards,S.: Crisis and reform in Latin America: from despair to hope, World Bank, Oxford University Press, NY, 1995.

20 Por eso, en la literatura técnica, se los denomina “costos institucionales”.

${ }^{21}$ Es necesario aclarar que también implica calificación laboral, introducción de tecnología, costo decreciente de la corrupción, etc. La eficiencia económica no es solo cálculo racional y ajustes vía costos. 
capaces de concurrir al mercado mundial. El comercio internacional es ahora el incentivo principal del desarrollo económico, por ende una economía moderna es aquella que se orienta por las señales que envía el mercado a nivel mundial y ya no la estrategia del desarrollo nacional.

En ese contexto las privatizaciones cumplieron dos objetivos explícitos: la baja del gasto público y el fortalecimiento del sector privado. El primero suponía un objetivo articulado a la estabilidad monetaria, pues la estrategia mercado internista había requerido de una intervención del Estado en la economía a través, principalmente, de las empresas públicas. Estas políticas económicas de Estado propendían al desarrollo económico pero también social y regional, por ende su lógica global no necesariamente respetaba la ecuación económica costos-beneficios. De ahí que el estricto balance fiscal no fuera una meta prioritaria. En la medida de la crisis del modelo, el costo fiscal del mismo aumentó a la vez que los resultados de la inversión pública en la economía eran claramente negativos. Por lo tanto la economía estatal pasó a ser una cuestión fiscal y la contención del gasto público un objetivo de las reformas económicas. En ese sentido, las privatizaciones implicaron ahorro de gasto fiscal (inversión pública) ineficiente.

El segundo objetivo implicó el traspaso de una estructura económica (comunicaciones, transporte, commodities, empresas extractivas, energía, etc.) clave del desarrollo económico post-crisis al sector privado. Esto significaba adecuarse a los nuevos tiempos de la economía privada a la vez que una excelente oportunidad de negocios, dado que las empresas a privatizar tenían un potencial económico impresionante con solo mejorar la inversión en ellas. Dada la liquidez monetaria existente en el mercado financiero internacional y la acumulación de capital en muchos mercados nacionales, la financiación de dicha inversión era posible, con lo cual se cerraba, en términos de lógica económica, la posibilidad de avanzar en las políticas de privatizaciones ${ }^{22}$.

Por último, las reformas financieras engloban todo el proceso de transformaciones económicas. Por un lado porque suponen adecuarse a los lineamientos económicos y tecnológicos de la globalización. Los primeros implican la necesidad de contar con un contexto económico mundial, es decir donde las transacciones financieras solo encuentren límites propios. Los segundos implican las condiciones materiales que viabilizan esos desplazamientos de activos financieros. El bien que

\footnotetext{
${ }^{22}$ Un tercer elemento, no menos importante, fue la posibilidad que las privatizaciones ofrecieron para hacer efectivo el cobro de parte de las deudas externas a partir de los diferentes mecanismos de "capitalización de la deuda”.
} 
se desplaza es virtual, por ende, es el bien mas factible de ser intercambiado en tiempo real con recursos tecnológicos apropiados. Es en este sentido que se acopla la tecnología informática a la reproducción dinámica de activos financieros.

Por otro lado, las reformas financieras estructuran una modalidad de circulación de capital en igual sentido que la circulación comercial, es decir a partir de las linealidades de mercado y ya no del Estado o las economías nacionales. Las reformas financieras se instrumentaron para autonomizar al máximo posible el bien dinero, sus modalidades de reproducción (préstamos, créditos, intercambio de activos, financiamientos, etc.) y su precio (tasa de interés) de las regulaciones estatales y, principalmente, del uso que el Estado le dio al capital financiero antes de las reformas.

Por otra parte, y como condición necesaria, se debe observar que esta transformación de la circulación financiera a nivel mundial se desarrolló en un marco de sobreliquidez monetaria internacional en los últimos 20 años. Esta presión de dinero, y luego activos financieros, autonomizó al capital financiero de manera tal que se comenzó a reproducir desde una lógica propia de acumulación. Definitivamente, el capital financiero dejó de ser un soporte de la producción de bienes y pasó a transformarse en un bien propio, capaz de generar sus propias condiciones de reproducción. Así las reformas financieras se pueden observar en un contexto de liberalización de las economías a nivel mundial, pero también por sus condiciones materiales, es decir su crecimiento estructural y su capacidad progresiva de desplazamiento.

Este análisis de las políticas de reformas económicas procuró detenerse mínimamente en la lógica de las mismas, es decir en el sentido que esas reformas tenían. Trató de ver por que las reformas económicas utilizaron ciertos instrumentos y no otros y cual era el escenario económico al que se tendía al fin de las reformas. En este sentido, se puede convenir en que generar una nueva estructura económica era un fin en sí mismo.

Pero también existía otro objetivo explícito: un nuevo patrón de crecimiento económico. Las reformas económicas se posicionaban desde un diagnóstico de crisis, por el cual se consideraba agotado el modelo de crecimiento de posguerra (keynesiano). La propuesta de transformaciones entonces se justificaba por la necesidad de retomar el camino del crecimiento económico pero, dada la crisis, reformulando los mecanismos e instituciones económicas. Se pasa así a una economía de la oferta (supply-side) o, en términos socioeconómicos, al auge del neoliberalismo. 
La propuesta del neoliberalismo se sintetiza en una idea muy simple, permanentemente utilizada y con la que se convenció a casi todas las sociedades acerca de la necesidad de instrumentar dichas transformaciones. Esta idea se sintetizaba en un esquema que igualaba crecimiento económico con empleo y, luego, con bienestar socioeconómico. El objetivo era alcanzar los estándares de bienestar económico de la segunda posguerra. El punto era que se debían variar los mecanismos y los comportamientos sociales y laborales que el exceso de bienestar (a través del gasto abusivo del Estado) habían introducido en ese patrón de crecimiento.

La propuesta principal para la generación de ese nuevo esquema socioeconómico consistía en priorizar el crecimiento de la economía. Para eso se debía incentivar especialmente a los productores de bienes, esto es las empresas. La mejor manera de lograr ese incentivo era a través del sistema impositivo, bajando al mínimo posible las imposiciones a las empresas para que éstas, con los recursos ahorrados, redoblen la inversión y generen más bienes. Retomando inconcientemente ciertas ideas del esquema keynesiano, se suponía que la capacidad de producir más implicaría mas creación de empleos, mejores sueldos y mas capacidad de consumo de la sociedad que, ahora, no debería esperar ese consumo de la provisión del Estado sino de su propio esfuerzo. Para eso se requería regenerar el sentido de autorresponsabilidad en la reproducción de la propia vida cotidiana de los actores sociales, desarmando el sistema de provisión estatal (welfare) que, de acuerdo a las hipótesis neoconservadoras había desvirtuado las características individuales y sociales que posibilitaron la economía capitalista.

Concretamente, para volver a alcanzar los estándares de vida de antes de la crisis la economía debía volver a crecer. El Estado, tras la crisis fiscal que acorde a este diagnóstico fue causada por las provisiones sociales, ya no podía, ni debía, ser el motor del crecimiento económico. Este era potestad de los individuos, es decir del mercado al que concurrían. Una vez recuperado el crecimiento ineludiblemente la riqueza se distribuiría por el mismo mecanismo de mercado. De ahí el nombre de este esquema: teoría del "derrame”, "goteo" o "spill over.”

\section{REFORMA DEL ESTADO: DEL MERCADO A LAS REFORMAS DE “SEGUNDA GENERACION”}

La principal cuestión institucional en el proceso de reformas iniciado a fines de los '80 y principios de los '90 en América Latina fueron las reformas estatales. La lógica principal de este proceso político residió en la reconversión del eje Estado-Mercado que, en América Latina, se posicionó sobre el primer término del 
mismo desde mediados de siglo. Si las reformas globales implicaban sustancialmente la vuelta, o la creación, del mercado, la tarea de primer orden era reformar los estados de manera tal que, principalmente, perdieran su capacidad material, política y simbólica de direccionalizar la reproducción social. Después de todo esa había sido su tarea y, en algunos casos, su logro, fundamental.

Las políticas de reformas estatales combinaron la ortodoxia del Banco Mundial y las especificidades históricas que hacían de cada Estado latinoamericano una estructura institucional particular, con capacidades particulares de intervención y legitimaciones diferenciadas ante la sociedad. Por ende las políticas concretas de reformas, es decir la desarticulación de esa capacidad de intervención sobre todo en la economía y el mercado de trabajo, tomaron formas e implementaron instrumentos acordes a la dimensión de los estados y la capacidad reformista (en función de su legitimidad) de los gobiernos.

Si desde lo económico, las reformas estatales supusieron privilegiar los mecanismos del mercado para un nuevo modelo de desarrollo económico ${ }^{23}$, en la cuestión social la desestructuración de la intervención estatal en los ordenamientos sociales $^{24}$ se intentó desplegar a partir de fortalecer la sociedad civil y, dentro de ésta, el ahora llamado "tercer sector" 25 . El diagnóstico quizás era acertado pero incompleto, dado que se situaba al problema en torno a las carencias sociales que producía la reestructuración económica pero no se señalaba la desarticulación del lazo social y la perdida de sentidos de pertenencia sociales que la retirada del Estado provocaba en grandes grupos sociales, sobre todo los vinculados al mercado de trabajo. El punto es que la influencia del Estado en el mercado de trabajo, me-

\footnotetext{
${ }^{23}$ Y de ahí la importancia de las políticas de privatizaciones de empresas públicas, las descentralizaciones de servicios públicos, la desregulación financiera, los acuerdos fiscales regionales, etc. en los procesos de reformas estatales.

${ }^{24}$ Básica, pero no únicamente, las políticas de empleo, de sostenimiento de los salarios, políticas sociales y la legitimación de la cultura del Estado.

${ }^{25}$ Dos acotaciones: por un lado la recreación de la sociedad civil asoma como una cuestión de primer orden en las sociedades latinoamericanas dada la fuerte impronta estatista en la conformación de identidades sociales y, en algunos casos, el autoritarismo social que ella introdujo en sectores sociales. Pero cabe sospechar que no son solo buenas intenciones las que imperan en esta "convocatoria" sino que más bien prima el intento de bajar los costos fiscales de las intervenciones sociales del Estado y legitimar, o al menos desenfocar, ciertas situaciones sociales graves productos de las reformas económicas. Por otro lado, el concepto del tercer sector apoyaría esta idea en tanto se intenta trasladar a organizaciones sociales autónomas y voluntarias, tareas de rearticulación social altamente costosas en razón de las situaciones de partida, de las necesidades materiales y de los costos de legitimación política que tales situaciones acarrean. Sobre el "tercer sector": Gorz,A.: Metamorfosis del trabajo, Op. Cit..; Rifkin,J.: El fin del trabajo, Planeta, Bs.As., 1997.
} 
diante políticas de empleo, tornaron al mismo como el eje dinámico en términos de conferir sentidos socialmente integradores, y la relación Estado-Sociedad constituida desde mitad del siglo cobraba especial significación desde la estructuración de un cierto tipo de mercado de trabajo.

Una vez estructurado un nuevo modelo de crecimiento económico, concretamente instituido el mercado, se comenzaron a advertir ciertos problemas sociales que, si se puede discutir que no son causados directa o intencionalmente por las reformas, se debe acordar que son un producto de las nuevas estructuras económicas. Nos referimos, como ya se señaló, a las dimensiones del desempleo abierto, la precarización de los contratos laborales, la disparidad en la distribución de ingresos y la aparición de franjas muy flexibles y vulnerables que visibilizan nuevas situaciones de pobreza.

El problema con esta nueva situación social ${ }^{26}$ es que, en las condiciones del discurso prevaleciente, debieran resolverse según las reglas del mercado, sea por la provisión de bienes económicos que éste desarrolle y expanda hacia la sociedad, o a partir de mecanismos y estrategias de desarrollo social propias que la misma sociedad -grupos sociales autónomos- elaboren desde su propia cultura ${ }^{27} \mathrm{y}$ lógicas sociales de organización. Pero la realidad mostraba progresivamente que el mercado no se constituía en una institución de provisión de bienes sociales sino que funcionaba con una lógica específica de rentabilidad por la cual no se responsabilizaba de sus márgenes. Dado que la nueva economía propuesta desarrollaba formas de organización y estrategias de acumulación necesariamente desde la perspectiva de la ganancia, aumentaba permanentemente sus márgenes externos. Peor si esos márgenes -bolsones de desempleo, precariedad y pobreza- que en un primer momento intentaron ser presentados como los "costos transitorios del ajuste” terminaron siendo estructurales. La velocidad del cambio tecnológico y los saberes laborales producían "exiliados permanentes” entre quienes en algún momento salieron del mercado formal del trabajo. Desde ahí se comenzaba a tran-

\footnotetext{
${ }^{26}$ Que en su conjunto y una vez dotada de su especificidad institucional conforman lo que definimos como marginalidad social, y se transforma así en lo que Castel llama "cuestión social” y que debe entenderse quizás, como la emergencia de una nueva situación social que se entiende en si misma y constituye un campo propio de problemas.

${ }^{27}$ La posibilidad de esta salida se observa desde dos visiones diferentes: la neoliberal (a lo Hernando de Soto) que proclama la liberación de las potencialidades creativas de los individuos para desenvolverse en la economía sin la injerencia de los estados, y una versión "sui generis" del populismo que enfocaba en la economía popular de desarrollo, es decir el desenvolvimiento de actividades económicas por parte de grupos cultural y socialmente homogéneos con mecanismos y lógicas ni de mercado ni estatistas, la alternativa a la pobreza que generaban las reformas neoliberales.
} 
sitar el sendero de la marginalidad, en donde, al final del camino, llegaban algunos sujetos ya sin ningún sentido social de pertenencia.

Hay quienes sostienen que el mercado, es decir el crecimiento económico de mercado, debe corregir esas situaciones y hay quienes sostienen que la culpa de esas situaciones son del individualismo utilitario del mercado. No es el punto discutir esas posiciones pero si entender que no está en la lógica de la economía de mercado distribuir socialmente su producto. De ahí que lo único cierto es que los problemas sociales de la nueva cuestión social no los resuelve, ni debe esperarse que lo haga, el mercado. En algún momento de este debate el discurso prevaleciente reconoció la necesidad de volver a pensar en el Estado, en reintroducir el Estado para hacer frente a la cuestión social.

Este reflujo hacia la cuestión del Estado y sus niveles de participación están presentes en toda su dimensión en un informe del Banco Mundial de $1997^{28}$. Este informe reconoce solo implícitamente que el Estado ya no puede estar ausente en los nuevos ordenamientos económicos y sociales post-reformas. Posiblemente, en el fondo opere un reconocimiento acerca de la crisis de las ideas optimistas sobre las potencialidades globales del Mercado, tal como imperaban en plena aplicación de las políticas de reformas.

Comenzando por posibles conclusiones, el problema de este informe es que sitúa la necesidad de repensar el Estado y las políticas públicas en un sentido netamente complementario del mercado. Mas aún, el problema radica en conceptualizar al Estado no como elemento auxiliar del mercado sino a partir de las carencias que este generó una vez reformadas las economías en América Latina. El problema que viene a resolver el Estado consiste en garantizar, suplementar y estabilizar política y socialmente ciertas cuestiones que las reformas de mercado no pueden, o no quieren en el sentido que no es de su racionalidad, asumir. Si bien se enuncia replantear el papel del Estado, lo que realmente se propone es un nuevo modelo de Estado que, mas allá de posibles características universales, el punto mas significativo es su posicionamiento como apéndice de una nueva situación económica, social y cultural. De ahí su conceptualización en torno a la idea de "reformas de segunda generación".

Para el Banco Mundial el nuevo rol del Estado en las sociedades postreformas ya no es asumir competencias como proveedor exclusivo de bienes ma-

\footnotetext{
${ }^{28}$ Banco Mundial: Informe sobre el desarrollo mundial. El Estado en un mundo en transformación, Washington, 1997.
} 
teriales y simbólicos, sino promover la capacidad social en torno a esa provisión y regular la producción de ciertos bienes públicos ${ }^{29}$. El Estado ya no tiene ante si una economía árida y sin capacidad de financiamiento y racionalidad empresaria. Tampoco una sociedad inerte o poco socializada en una cultura política propia de sociedades complejas. Junto a él se desarrolla una economía en expansión, direccionalizada por la lógica de la acumulación y la propiedad privada. También, a las sociedades recién incluidas de mediados de siglo, las reemplazan sociedades en plena expansión de sus ciudadanías y los derechos inherentes a ellas. Por ende el Estado ya no debe crear las condiciones económicas y políticas propias de una etapa de inclusión y desarrollo social. El punto ahora pasa por “....su capacidad de emprender y promover acciones de interés colectivo en forma eficiente” ${ }^{30}$, para atender el bienestar de la población. Entiéndase, las acciones privadas y públicas las desarrolla una sociedad de ciudadanos. El interés colectivo que debe devenir de algunas de esas acciones deben ser propuestas, no diseñadas e implementadas, por el Estado.

Por otra parte, este funcionamiento del Estado le permite no sobreactuar, es decir, no generar propuestas y, por ende, políticas, estructuras institucionales y burocracias administrativas, por fuera de su capacidad. Si es la sociedad la que propone sus propios ordenamientos, el Estado acompaña, promueve, y apuntala, pero no genera, no crea. Esto posibilita la adecuación, eternamente perseguida por las concepciones liberales del Estado, de equiparar funciones, capacidades y tamaño.

Si se resumen las propuestas acerca de las áreas básicas de intervención de los nuevos estados, estas son:

-establecimiento de un orden jurídico básico;

-mantenimiento de un entorno de políticas no distorsionantes, incluida la estabilidad macroeconómica;

-inversión en servicios sociales básicos e infraestructura;

-protección de los grupos vulnerables;

-defensa del medio ambiente ${ }^{31}$

Estas propuestas se sintetizan en el concepto elaborado por el Banco Mundial de "complementariedad Estado-Mercado"32. El mismo se define como la

\footnotetext{
${ }^{29}$ op.cit., pág..2

${ }^{30}$ op.cit., pág..3

${ }^{31}$ op.cit., pág..4

${ }^{32}$ Informe Banco Mundial, op.cit.
} 
garantía y el asentamiento de bases institucionales (sistema jurídico-normativo, estabilidad, derechos de propiedad, seguridad pública, mecanismos contra la corrupción) que el Estado debe proveer para un correcto funcionamiento del mercado, eje de la dinámica social. El Estado, así, se define en torno a las modalidades de los mercados, los cuales generan permanentes demandas institucionales en la medida de su constante transformación. De esta manera se acotan los interlocutores válidos del Estado: "La eficacia del Estado es mayor cuando se ensancha la opinión del sector empresarial y de la ciudadanía en general y se propone la participación de ambos grupos en la determinación y aplicación de las políticas”33. Es evidente que cuando se precisa un actor social (en este caso el empresariado) y se generaliza otro (la ciudadanía), se posiciona a aquel como real interlocutor. El resto debe ser tenido en cuenta solo como factor necesario de legitimación de la relación Estado-Mercado (empresarios).

Se puede apreciar también en esta concepción que tanto el Estado como el Mercado son considerados sujetos sociales, es decir generadores de una lógica de acción social específica. Por ende, son sus funciones, necesidades y legitimidades constitutivas las que deben impregnar de sentido al conjunto de la sociedad. Si se agudiza este análisis aparecen los actores que encarnan a estos sujetos: el sector empresarial como actor del mercado, y la ciudadanía en general como actor del Estado. Pero en última instancia estos actores son constituidos en la lógica de sus sujetos de pertenencia. Por lo tanto todo es pensable desde el Mercado, como dinámica del sistema social, y el Estado, como su condición de posibilidad (no de necesariedad), hacia los empresarios y los ciudadanos que, en tanto actores, son históricos. En cambio, el sujeto Mercado-Estado es ahistórico. Es propio de la organización moderna de la sociedad humana.

En resumen, las reformas de "segunda generación” están pensadas para cubrir, desde la gestión estatal, las falencias y vacíos que las reformas económicas de mercado dejaron planteadas. Así se entienden las propuestas de desarrollar políticas de control y regulación, subsidiariedad, políticas sociales focalizadas, equidad y seguridad jurídica. La lógica social subyacente consiste en dotar al estado y la acción de los gobiernos de criterios de transparencia, equidad y responsabilidad (accountability) en la gestión de los asuntos públicos. Se prevé que la organización de la sociedad civil en grupos autónomos y con intereses particulares (modelo ONG's) posibilitaría al Estado desprenderse de la responsabilidad de los funcionamientos macrosociales.

\footnotetext{
${ }^{33}$ Informe Banco Mundial, op.cit.
} 
La hipótesis de este trabajo es que este planteamiento y los instrumentos a implementar dejan de lado una cuestión esencial: la reconstrucción del lazo social, la integración de los sectores sociales desplazados de la sociedad y la política y, definitivamente, la dotación de un sentido de pertenencia sin el cual no existe sociedad en un mundo que se plantea complejo, dinámico y flexible.

No implica lo antedicho que necesariamente el Estado debe ser el responsable de organizar y proveer de sentido de pertenencia a la sociedad. Pero si la política significa escenarios públicos, la re-inclusión de sectores sociales ahora excluidos permitiría ensanchar los márgenes de acción y legitimidad de los estados al tiempo que reconstruir capacidades políticas amplias a su interior.

Aparecen así dos cuestiones precisas: por un lado tomar en cuenta que, a diferencia de los estados sociales de fines del siglo pasado y principios del corriente, no se trata ahora de incluir en la esfera del Estado (y el sistema político) a nuevos sectores sociales. El desafío es mayor: se trata de sectores sociales excluidos pero que anteriormente (a la crisis de los '70-'80) estuvieron incluidos en la sociedad política con toda la amplitud que conceptualmente implica la ciudadanía social $^{34}$. Esto constituye un punto de primer orden pues implica una conciencia histórica de derechos, participación y pertenencia.

La otra cuestión que emerge, es pensar si efectivamente es el Estado el que debe resolver esta problemática social actual. Quizás sea tiempo de otro modelo de organización social y de reconstitución de la relación Estado-Sociedad. No se puede precisar una respuesta cierta pero si parece necesario que la transición entra una etapa de fragmentación social y la redefinición hacia un modelo social adecuado, hay un rol reservado al Estado que no puede eludirse: el generar certezas y respuestas a los grupos sociales que van, progresivamente, quedando en los márgenes de la "sociedad reconocida". Este problema se agudiza en tanto nos referimos a sociedades cuantitativa y cualitativamente dimensionadas, complejas y dotadas de estructuras tecnológicas que permiten rápidos desplazamientos y movilizaciones, sea de manera real o virtual. Al modo de la conciencia histórica, esta velocidad posible de los intercambios sociales y culturales obliga a respuestas y mecanismos reconstitutivos de lo social, aunque sean pensados como etapa de transición a otro modelo más horizontal de sociedad.

\footnotetext{
${ }^{34}$ Construcción social histórica como lo demostró Marshall. Marshall,T.H.: Citizenship and social development, Double Anchor Book, NY, 1964.
} 
En este contexto asoma la necesidad de repensar el Estado, y con él al sistema político, no solo en términos de estructuras institucionales e ingenierías políticas sino en su sentido principal: la articulación del conjunto de los sectores sociales.

\section{EL NUEVO CONCEPTO DE DESARROLLO LAS METAS DEL MILENIO}

Los resultados netos de las reformas económicas y sociales ${ }^{35}$ y las reflexiones teóricas acerca de los logros y déficits del nuevo consenso redefinieron sustancialmente la cuestión del desarrollo en su aspecto social, es decir como factor de modernización de la sociedad a partir del crecimiento económico. Se han propuesto consensos alternativos al Consenso de Washington a la vez que desde los mismos organismos multilaterales se han desarrollado propuestas correctivas y hasta superadores de los programas originales de reformas ${ }^{36}$.

Si la perspectiva de las instituciones multilaterales son señeras en términos de inducir políticas públicas, una modalidad de entender el nuevo concepto de desarrollo (económico y social) es tomar algunas elaboraciones de esos organismos. En este sentido una interpretación de las llamadas Metas del Milenio ofrecen una perspectiva significativa de comprensión. Se entienden, desde ahí, las formas y modalidades del desarrollo en el nuevo consenso.

La Cumbre del Milenio se realizó en el año 2000 a partir de un acuerdo realizado por mandatarios de países miembros de las Naciones Unidas, con el objetivo de reducir los niveles de pobreza. El diagnóstico que fundamentó las Metas el Milenio residió en las alarmantes cifras que demostraban el aumento de la pobreza y la indigencia ${ }^{37}$, a la vez que el objetivo de las "Metas...” era su reducción en términos de estándares aceptables a sociedades civilazadas y democráticas. El aspecto crítico que habremos de destacar en este acápite es la insuficiencia de la

\footnotetext{
${ }^{35}$ Debate denso, estadísticas amplias y posturas interesadas hacen de esta discusión algo fuera de los límites de este trabajo.

${ }^{36}$ Un punto de inflexión que comenzó con el informe del Banco Mundial de 1997, significativamente dedicado al papel del Estado. Banco Mundial: El Estado y sus transformaciones, Informe Mundial, NY, 1997.

${ }^{37} \mathrm{Si}$ los conceptos significan situaciones concretas, es importante hacer notar la construcción del concepto de indigencia como situación límite de la sobrevivencia. Por si misma, la indigencia habla de la evidente regresividad social en la distribución del crecimiento económico en los últimos veinte años.
} 
propuesta dado que fue elaborada en los lineamientos mismos de las políticas que concluyeron en la ampliación de la pobreza ${ }^{38}$.

Hacia 1999 la CEPAL ${ }^{39}$ estimaba que el 35\% de los hogares latinoamericanos estaban en situación de pobreza y, dentro de ese porcentaje, el 14\% en situación de indigencia. En términos de personas los porcentajes representaban el $44 \%$ de la población en situación de pobreza y el 18\% en estado de indigencia. A su vez esto significaba 211 millones de personas pobres y 89 millones de indigentes ${ }^{40}$ Los porcentajes mostraban una mejora respecto a iguales indicadores en 1990 pero obviaban señalar que 1990 fue el año de las crisis hiperinflacionarias o de altas inflaciones en América Latina, las cuales arrasaron con los empleos y los ingresos empobreciendo rápidamente a vastos sectores sociales. Pero en comparación, por ejemplo, a la década de los '60, los niveles de pobreza de 1999 eran escandalosos en su dimensión cuantitativa y en su significación social y política. Hablaban, concretamente, de una regresividad social alarmante.

El objetivo propuesto en las "Metas...” consistía en la reducción de la pobreza extrema en América Latina a la mitad para el año 2015. Para eso se desarrolló una base estadística que relacionaba el crecimiento económico y la pobreza. Desde esta base se estimó que para reducir la pobreza extrema a la mitad entre 1999 y 2015 se necesitaría una tasa de crecimiento del producto total en la región no inferior al 3,8\% anual o una tasa per cápita no inferior al 2,3\% anual. Obviamente se hablaba de crecimiento sostenido. Desagregado por grupos de países esta hipótesis señalaba que los países considerados como de mayor pobreza requerirían un crecimiento anual total del 5,7\% y per cápita del 3,5\%, los países de niveles de pobreza intermedia un crecimiento total anual del 2,7\% y per cápita del 1,4\%, y los de menor pobreza un crecimiento total anual del 2,5\% y per cápita de 1,3\%.

Es importante hacer notar que esta relación entre economía y sociedad se refería solo a la pobreza extrema. Esta se definía como aquella situación en la cual cada individuo percibía menos de un dólar al día.

\footnotetext{
${ }^{38}$ Para señalarlo resumidamente, una insuficiencia de la teoría del derrame (spill over) que no se debía a fallas del mercado sino a la carencia de instituciones adecuadas (por ejemplo, para controlar los niveles de corrupción).

${ }^{39}$ CEPAL: Panorama social para América Latina y el Caribe 2001-2002, CEPAL, Chile, 2002.

${ }^{40}$ En CEPAL: op.cit., se pueden observar esos porcentajes en cada país de América Latina y en comparación 1990-1999.
} 
Aquí es necesario profundizar en el análisis que nos ocupa. Independientemente de lo acertado de la hipótesis de las "Metas...” y la posibilidad de realizarla, ya no se habla de desarrollo y mucho menos de modernización social. La relación "virtuosa" de posguerra que equiparaba crecimiento económico con modernización social, y esto se denominaba desarrollo, había desaparecido conceptualmente del análisis socioeconómico. Su lugar lo ocupaba la relación entre crecimiento económico y “alivio de la pobreza”41.

El desarrollo de esta relación se consideraba la mejor, y quizás única, alternativa posible. Incluso en el documento oficial de las "Metas..." se consideró un objetivo adicional, es decir si fuera posible y tuviese éxito el objetivo principal, que era la posibilidad de reducir también a la mitad la pobreza total ${ }^{42}$. Concretamente, la cuestión social, producto o efecto del crecimiento económico, pasó a ser la pobreza en vez de la modernización, por ende la sobrevivencia en lugar de los derechos sociales.

Otro aspecto necesario del análisis, tomando como dado que se refiere únicamente a la relación entre crecimiento económico y niveles de pobreza ${ }^{43}$, debe consistir en verificar dicha relación ya que ella se presenta como absoluta en todos los documentos de los organismos multilaterales.

Saliendo ya de las "Metas...", sobre todo en su periodización histórica, América Latina como región, y la mayoría de sus países componentes, observaron en los dos últimos años (2003 y 2004), y posiblemente los datos de 2005 sean equivalentes, un crecimiento alto y sostenido de sus economía. El crecimiento del producto interno bruto total fue de $2,0 \%$ en 2003 y 5,9\% en 2004. El crecimiento del producto interno per cápita fue de 0,5\% en 2003 y 4,4\% en 2004.

A su vez, el crecimiento del producto interno bruto observó picos como el de Argentina (8,8\% en 2003 y 9,0\% en 2004), Uruguay (2,2\% y 12,3\% respectivamente), Panamá (4,3\% y 6,2\%), Chile (3,7\% y 6,1\%) y Ecuador (2,7\% y 6,9\%). Es decir, una relativa cantidad de países que inhibe de hablar de casos aislados $\mathrm{y}$,

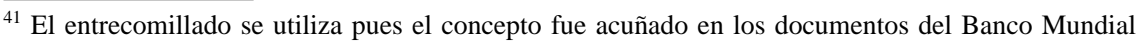
desde fines de los '90.

${ }^{42}$ Para esto se requeriría un crecimiento anual sostenido del 2,6\% para la región o 4,8\% para los países más pobres, 2,8\% para los medianamente pobres y 1,7\% para los menos pobres.

${ }^{43}$ Se insiste en este punto pues es el verdadero giro de la nueva economía, es decir la imposibilidad de referir el crecimiento económico a las mejoras progresivas y constantes de los niveles sociales de vida. Reitero, lo que antes se denominaba "desarrollo".
} 
por otra parte, marca la progresividad del crecimiento tal cual muestran las cifras de 2004. Excepto los casos de Haití y Granada ningún país de la región observó un crecimiento negativo del producto, a la vez que más del 75\% de los países crecieron en 2004 a tasas superiores al 4\%. Concretamente, uno de los aspectos de la relación trazada en las "Metas..." ${ }^{44}$-el crecimiento económico- se está cumpliendo en América Latina. Sin embargo, el otro aspecto -la reducción de la pobreza- no evoluciona de acuerdo a la hipótesis original.

Entre el año 2000 y el año $2005^{45}$ la pobreza solo disminuyó del 42,5\% de la población a 40,8\% y la indigencia del 18,5\% al 16,8\%. En millones de personas, la pobreza disminuyó de 214 millones en 2001 a 213 millones en 2005 y la indigencia de 92 millones a 86 millones.

Evidentemente la dinámica del crecimiento económico no se está condiciendo con un efecto equivalente en términos de reducción de la pobreza y la indigencia. Con lo cual la relación expuesta en las "Metas...” y otras formulaciones muestran una extrema debilidad.

La pregunta sería, entonces, cual es el punto que debilita la relación mencionada. Una primera respuesta aparece hoy como bastante evidente: la distribución de los ingresos, es decir la modalidad en que se distribuye el producto del crecimiento económico. Una segunda respuesta, menos trabajada pero, entiendo, sustancial, consiste en el error de presuponer que el mercado, o la economía tal cual hoy está planteada, es la responsable de mejorar la distribución de los ingresos. La propuesta alternativa consiste en pensar que una distribución de los ingresos que realmente mejore la situación social es responsabilidad, y única posibilidad, de la política, lo que es decir de la acción de los gobiernos. Con lo cual nos situaríamos en el plano de la re-distribución de los ingresos sociales.

\footnotetext{
${ }^{44}$ En realidad en esta relación se piensa la cuestión social en la ortodoxia económica, los organismos multilaterales y la mayoría de los gobiernos, sobre todo del G7.

${ }^{45}$ Para el año 2005 porcentajes preliminares en base a 18 países elaborados por la CEPAL. Ver CEPAL: Panorama social de América Latina 2005, Informe Preliminar, CEPAL, Chile, 2005.
} 
Por el primer punto, la CEPAL sostiene que para una reducción del índice de Gini ${ }^{46}$ del $2 \%{ }^{47}$, lo cual significa mejorar la distribución de los ingresos y por ende aliviar la pobreza, las economías deben crecer a una tasa anual de 0,9\%, permitiendo esta relación acercarse a las "Metas..." incluso en menor tiempo al estipulado. A su vez entiende que esta posibilidad reside básicamente en las condiciones de las economías (recursos productivos, patrimonios físicos, dotación de recursos humanos, recursos financieros, etc.).

Nuevamente, una relación automática entre el funcionamiento de la economía y la cuestión social, esta vez mediatizada por condiciones estructurales que permitan una mejor distribución de los ingresos. Paradójicamente a este análisis, o relación, los países de la región con peor distribución del ingreso son los más dinámicos económicamente-Chile, Brasil-, mientras que otros países -Argentina, Ecuador- que se han recuperado de una profunda crisis en los tres últimos años creciendo fuertemente, no han logrado mejorar la distribución de los ingresos.

Entonces el segundo punto: si el crecimiento económico no mejora de manera equivalente la distribución de los ingresos, esto debe ser responsabilidad política y debe vehiculizar la acción estatal (política tributaria, salarios mínimos, formalización del empleo, apoyo a a sectores productivos, etc.). La falta de énfasis en el rol estatal para la mejora en la distribución de los ingresos deviene precisamente de la conceptualización de esa cuestión, por la cual se entiende que los ingresos se distribuyen naturalmente en la economía ${ }^{48}$ en lugar de pensar que los ingresos se captan socialmente en cada economía. Concretamente, la distribución, en realidad captación, de los ingresos es un producto del estado vigente de la rela-

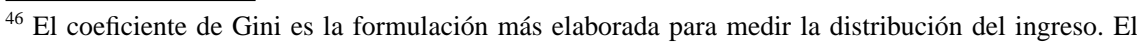
mismo, en una escala de 0 a 1 o de la distribución más perfecta a la más imperfecta, permite ver que en una economía cuanto más cerca de 0 esté el índice la distribución es más progresiva, mientras que cuanto más cerca de 1 esté el índice la distribución es más regresiva. Otra modalidad es dividir a los sectores perceptores de ingresos en deciles y luego comparar entre el de más altos ingresos (decil 10) y el de más bajos ingresos (decil 1). A mayor diferencia entre deciles mayor regresividad.

${ }^{47}$ Corresponde a una reducción de 0,01 del coeficiente.

${ }^{48}$ Entendiendo a la economía (mercado) como ahistórica y no relativizándola por las nuevas modalidades de producción -tecnología- y acumulación -tasa de ganancia-, a pesar de ser evidente que la actual etapa de la economía mundial se caracteriza por la concentración de capital, recursos y, por ende, ganancia, la orientación de los sectores más dinámicos al mercado global (impidiendo la circulación de capital en forma dinámica en el mercado interno) y la predominancia del sector financiero en la formación de la ganancia (renta). En una idea que da para abundar mucho, la tasa de ganancia de una economía se autonomizó relativamente de los niveles de desempleo y pobreza de la sociedad.
} 
ción entre los distintos sectores sociales y no un atributo natural de la economía. Es, por ende, una cuestión más política que económica ${ }^{49}$.

Sintetizando, ya no se piensa ni se conceptualiza la cuestión social en términos de desarrollo. Su reconfiguración como pobreza implica un acotamiento de esa cuestión pero, sobre todo, simboliza la regresividad social que se ha desplegado en América Latina en los últimos años. Revertir esta situación exige políticas que se fundamenten en criterios de equidad y justicia, y que entiendan que el combate a la pobreza es solo una primer y necesaria etapa en la reconstitución social en la región. De lo contrario solo se consolida un "status quo" reñido con todo criterio de ética y moral pública pero también generador de situaciones políticas que tienden a la inestabilidad y el conflicto.

\section{REFERENCIAS BIBLIOGRAFICAS}

Altimir, O., (1997), "Desigualdad, empleo y pobreza en América Latina: efectos del ajuste y del cambio en el estilo de desarrollo", en Desarrollo Económico $\mathrm{N}^{\mathrm{o}} 145$.

Altimir, O y Beccaria., L., (2000)., "La distribución del ingreso y el nuevo orden económico", en Socialis No 2.

Banco Mundial., (1993)., “América Latina y el Caribe: diez años después de la crisis de la deuda”, Informe sobre el Desarrollo Mundial 1993, Washington.

Banco Mundial., (1997), "El Estado en un mundo en transformación”, Informe sobre el desarrollo mundial 1997, Washington D.C.

Banco Mundial., (2004), Desigualdad en América Latina y el Caribe, ¿ruptura con la historia?,www.worldbank.org

'90”, Borón, A., et. al., (comps.), Tiempos Violentos. Neoliberalismo, globalización y desigualdad en América Latina, CLACSO, Bs. As.

Bourdieu, P., (2001), La miseria del mundo, FCE, México.

Bouzas, R., (coord.), (2002), Realidades nacionales comparadas, OSDE/Altamira, Bs. As.

Bresser Pereira,L., (1991), “La crisis de América Latina: Consenso de Washington o crisis fiscal”, en Pensamiento Iberoamericano Nº19.

Calderon, F., (comp.),(1986), Los movimientos sociales ante la crisis, CLACSO, Bs. As.

\footnotetext{
${ }^{49}$ Una forma de objetivar esta idea es observar dinámicamente, incluso por cortes históricos, el \% del PBI que se distribuye en salarios e ingresos.
} 
Camou, A., (2001), Los desafíos de la gobernabilidad, FLACSO, Mexico.

Castel,R., (1997), La metamorfosis de la cuestión social, Una crónica del asalariado, Paidós, Bs. As.

Cavarozzi,M., (1991), Beyond transitions to democracy, ponencia presentada en el Primer Congreso Mundial de Ciencia Política, Buenos Aires.

CEPAL, (1994), El gasto social en América Latina: un examen cuantitativo y cualitativo, Santiago.

CEPAL, (1995), Panorama social de América Latina 1994, Santiago.

CEPAL, (2003), Balance preliminar de las economías de América Latina y el Caribe, Santiago.

CEPAL, (2002), Panorama Social de América Latina 2002, www.eclac.cl

CEPAL, (2004), Panorama Social de América Latina 2003, www.eclac.cl.

CEPAL, (2005), Panorama Social de América Latina 2005. Informe Preliminar, www.eclac.cl

Damill,M.y Frenkel,R.(1996. "De México a México: el desempeño de América Latina en los noventa”, en Desarrollo Económic, Vol. 36.

Duhau, E. (1997), “Pobreza, ciudadanía y política social en América Latina”, en Ciudades,(36).

Fitoussi,J. y Rosanvallon,P., (1997), La nueva era de las desigualdades, Manantial, Bs. As.

Foxley,A. (1982): Experimentos neoliberales en América Latina, CIEPLAN, Santiago.

Foxley,A., (1987), "El problema de la deuda desde una perspectiva latinoamericana”, en Desarrollo Económico No 106.

Frenkel,R., (1996), “Políticas antiinflacionarias en América Latina”, en Agora No 5.

Germani, G., (1980), Política y sociedad en una época de transición, Piados, Bs.As.

Huntington,S., Crozier,M. y Watanuki,J., (1975), The crisis of democracy. Report on the governability of societies, NY Press, NY.

Labastida Martin del Campo, J, et. al. (comps.), (2001), Globalización, identidad y democracia. México y América Latina, Siglo XXI, México.

Revista Pensamiento Iberoamericano (1998), América Latina después de las reformas, BID, Madrid.

Revista Pensamiento Iberoamericano No 19, (1991), La encrucijada de los noventa América Latina, Madrid.

Stiglitz, J. (1998): "Más instrumentos y metas más amplias para el desarrollo. Hacia el consenso Post-Washington”, en Desarrollo Económico Vol. 38, (151). 